\title{
PENGARUH LATIHAN PASSING BAWAH MENGGUNAKAN SASARAN TEMBOK (WALL BOUNCE) DAN PASSING BERPASANGAN MENGGUNAKAN TALI TERHADAP KEMAMPUAN PASSING BAWAH DALAM PERMAINAN BOLA VOLI KLUB PUTRA MONTONG BAAN LOMBOK TIMUR TAHUN 2019
}

\author{
Ali Muhaimi ${ }^{1}$, P. Muhammad Yusuf ${ }^{2}$ \\ ${ }^{I}$ Dosen Jurusan Pendidikan Olah Raga Fakultas Pendidikan Olah Raga Dan Kesehatan, IKIP \\ Mataram, Provinsi Nusa Tenggara Barat. \\ ${ }^{2}$ Dosen Jurusan Pendidikan Olah Raga Fakultas Pendidikan Olah Raga Dan Kesehatan, IKIP \\ Mataram,Provinsi Nusa Tenggara Barat. \\ Email: alimuhaimin33@gmail.com
}

ALI MUHAIMIN (2019) dengan judul : "Pengaruh latihan passing bawah menggunakan sasaran tembok (wall bounce) dan passing berpasangan menggunakan tali terhadap kemampuan passing bawah dalam permainan bola voli klub putra Montong Baan Lombok Timur Tahun 2019. Skripsi, Fakultas Pendidikan Olahraga dan Kesehatan, Institut Keguruan dan Ilmu Pendidikan Mataram.

\begin{abstract}
Abstrak
Penelitian ini dilatar belakangi oleh pemain di klub putra Montong Baan yang masih belum menguasai passing bawah dengan baik, cara menerima bola masih belum benar khususnya pada saat bola awalan service musuh, dan program latihan untuk teknik dasar masih kurang. Penelitian ini bertujuan untuk mengetahui apakah melalui latihan menggunakan sasaran tembok (wall bounce) dan passing berpasangan menggunakan tali dapat meningkatkan kemampuan passing bawah dalam permainan bola voli pada pemain di klub putra Montong Baan Lombok Timur Tahun 2019. Metode yang digunakan dalam penelitian ini adalah eksperimen, penelitian ini termasuk dalam bentuk two group pretest-posttest design. Populasi dalam penelitian ini adalah pemain dalam klub putra Montong Baan berjumlah 10 orang, sedangkan sampelnya menggunakan study populasi di mana penentuan jumlah sampel dengan menggunakan seluruh populasi. Instrumen yang digunakan adalah tes (wall bounce) pantulan dinding. Teknik analisis data yang digunakan yaitu analisis statistik dengan pengujian hipotesis. Hasil analisis menunjukkan bahwa : ada pengararuh latihan passing bawah menggunakan sasaran tembok (wall bounce) dan passing berpasangan menggunakan tali terhadap kemampuan passing bawah bola voli pada klub putra Montong Baan Lombok Timur Tahun 2019. Dari data uji $t$ dapat dilihat bahwa nilai t-hitung kelompok eksperimen 1 sebesar 7,751 dan t- tabel sebesar 2,132, dan nilai t hitung kelompok eksperimen 2 sebesar 5,517 dan t-tabel sebesar 2,132 maka terdapat perbedaan yang signifikan terhadap kemampuan passing bawah. Hasil penelitian dan pembahasan dapat diambil kesimpulan bahwa ada pengararuh latihan passing bawah menggunakan sasaran tembok (wall bounce) dan passing berpasangan menggunakan tali terhadap kemampuan passing bawah bola voli pada klub putra Montong Baan Lombok Timur Tahun 2019.
\end{abstract}

Kata kunci :Pengaruh Latihan passing bawah menggunakan sasarn tembok (wall bounce) dan passing berpasangan menggunakan tali, Bola voli 


\section{PENDAHULUAN}

Permainan bola voli merupakan salah satu cabang olahraga permainan beregu yang di sukai dan di gemari setiap individu. Karena permainan bola voli termasuk olahraga yang menarik, menyenangkan dan tidak membutuhkan biaya yang besar sehingga bisa di lakukan dengan mudah. Cukup membutuhkan beberapa teman, bola, net dan lahan kosong yang bisa di jadikan lapangan maka permainan bola voli bisa di lakukan. Permainan bola voli memiliki beberapa bentuk teknik dasar yang perlu dikuasai oleh seorang pemain. Menurut Nuril Ahmadi (2007: 20) "dalam permainan bola voli ada beberapa teknik dasar yang harus dikuasai. Teknik dasar dalam permainan bola voli terdiri atas servis, passing bawah, passing atas, blok dan smash". Penguasaan teknik dasar sangat penting agar bisa bermain bola voli dengan baik. Tujuan awal dari permainan bola voli adalah bersifat rekreatif untuk mengisi waktu luang, namun seiring dengan perkembangan jaman, bola voli berkembang kearah tujuan-tujuan lain untuk mencapai prestasi tinggi, mengharumkan nama daerah, bangsa dan negara. Perkembangan permainan bola voli bukanlah secara kebetulan, hal ini dapat dilihat disetiap negara mempunyai organisasi bola voli sebagai wadah untuk membina para atlet, yang kemudian dapat mewakili pertandingan bola voli ditingkat Olympiade. Teknik permainan bola voli adalah bagian dalam permainan dalam melakukannya di tuntut aktivitas jasmani. Penguasaan teknik mutlak diperlukan, sebab jika salah teknik maka di anggap melakukan pelanggaran. Jadi penguasaan teknik yang benar sangat menentukan prestasi atau penentu kemenangan. Adapun teknik dasar dalam permainan bola voli meliputi: smash, passing, block, dan service.

\section{KAJIAN PUSTAKA}

\section{Hakikat Passing}

Passing adalah upaya seorang pemain dengan menggunakan suatu teknik tertentu untuk mengoperkan bola yang dimainkannya kepada teman seregunya untuk dimainkan di lapangan sendiri (Nuril Ahmadi, 2007:22).
Ditambahkan (M. Yunus, 1992:79) menjelaskan bahwa passing adalah mengoper bola kepada teman satu regu dengan suatu teknik tertentu, sebagai langkah awal untuk menyusun pola serangan kepada lawan.

\section{Hakikat Passing bawah}

Menurut Barbara L. Viera (2004: 19), passing bawah atau operan lengan bawah merupakan teknik dasar bola voli yang harus dipelajari lebih tegasnya Barbara mengatakan bahwa "Operan ini biasanya menjadi teknik pertama yang digunakan tim bila tidak memegang servis. Operan ini digunakan untuk menerima servis, menerima spike, memukul bola setinggi pinggang ke bawah dan memukul bola terpantul di net" Menurut Nuril Ahmadi (2007: 23) mengatakan ada beberapa tahap dalam melkaukan passing bawah yaitu :

a. Persiapan

1.) Bergerak ke arah datangnya bola dan atur posisi tubuh.

2.) Gengam jemari tangan.

3.) Kaki dalam posisi meregang dengan santai, bahu terbuka lebar.

4.) Tekuk lutut, tahan tubuh dalam posisi rendah.

5.) Bentuk landasan dengan tangan.

6.) Sikut terkunci.

7.) Lengan sejajar dengan paha.

8.) Pinggang lurus.

9.) Pandangan ke arah bola

b. Pelaksanaan

1.) Terima bola di depan badan.

2.) Kaki sedikit diulurkan.

3.) Berat badan dialirkan ke depan.

4.) Pukullah bola jauh dari badan.

5.) Pinggul bergerak ke depan.

6.) Perhatikan bola saat menyentuh lengan. Perkenaan pada lengan bagian dalam pada permukaan yang luas di antara pergelangan tangan dan siku.

c. Gerak Lanjutan

1.) Jari tangan tetap digenggam.

2.) Siku tetap terkunci.

3.) Landasan mengikuti bola ke sasaran.

4.) Pindahkan berat badan ke sasaran. 
5.) Perhatikan bola bergerak ke sasaran.

\section{Rancangan Penelitian}

Penelitian ini menggunakan metode eksperimen. Metode yang menggunakan suatu gejala yang disebut latihan. Dengan latihan yang diberikan tersebut akan terlihat hubungan sebab akibat sebagai pengaruh dari pelaksanaan latihan. Metode eksperimen dengan matched by subjects yang disingkat M-S adalah pemisahan pasangan-pasangan subjek masing-masing ke grup kontrol dan ke grup eksperimen secara otomatis akan menyeimbangkan ke dua grup itu.

Menurut Sutrisno Hadi ( 2000 : 260 ) bahwa "tiap-tiap eksperimen pada akhirnya harus membandingkan sedikitnya dua kelompok atau lebih menjadi kegiatan utama dalam penyelidikan-penyelidikan ilmiah".

Metode eksperimen adalah kegiatan yang meliputi tes awal, pemberian latihan, dan tes akhir. Untuk lebih jelasnya dapat digambarkan dengan rancangan sebagai berikut

\begin{tabular}{|l|c|c|c|}
\hline Kelompok & Pretest & Perlakuan & Posttest \\
\hline Eksperimen 1 & $\mathrm{O} 1$ & $\mathrm{X} 1$ & $\mathrm{O} 2$ \\
\hline Eksperimen 2 & $\mathrm{O} 1$ & $\mathrm{X} 2$ & $\mathrm{O} 2$ \\
\hline
\end{tabular}

Gambar 3.1. Tabel pretest - posttest control group design. Sumber : Sugiyono (2001: 64)

Keterangan :

O1 : Pretest yang dilaksanakan pada kelompok eksperimen

O2 : Postttest yang dilakukan pada kelompok eksperimen

X1 : Treatment. Latihan sasaran tembok (wall bounce)

X2 : Treatment. Latihan menggunakan tali.

Selanjutnya, populasi dalam penelitian ini adalah pemain di club bola voli putra Montong Baan Lombok Timur Tahun 2019 berjumlah 10 orang, Metode penentuan sampel pada penelitian ini adalah menggunakan metode study populasi. Study populasi adalah penentuan jumlah sampel dengan menggunakan seluruh populasi. Pada penelitian ini sampel yang digunakan adalah keseluruhan populasi pemain di klub bola voli putra Montong Baan
Lombok Timur Tahun 2019 berjumlah 10 orang.

Lebih lanjut, tehnik analisis data yang digunakan dalam penelitian ini adalah tes yang di gunakan dalam penelitian ini adalah tes kemampuan passing bwah ,sebelum dan sesudah latihan passing bawah dengan pantul dinding.

Teknik dokumentasi dalam penelitian ini digunakan untuk memperoleh data melalui catatan yang bersifat kuantitatif, data ini dapat bersifat pribadi atau pengalaman yang ditulis oleh subjek, data yang diperoleh dari pengamatan langsung yang diperkuat oleh peneliti dengan menggunakan teknik dokumentasi dalam mengumpulkan data. Dokumentasi diperlukan dalam penelitian kuantitatif, karena menghasilkan deskriptif yang berharga dan digunakan untuk mengolah segi-segi subjektif dan hasil yang dianalisa

secara induktif. Metode dokumentasi ini peneliti untuk mendapatkan data tentang jumlah anggota dan nama-nama Pemain pada klub voli putra Montong Baan Lombok Timur Tahun 2019.

Adapun analisis data tersebut menggunakan rumus t-test yang sebelumnya harus di ketahui perbedaan mean dengan menggunakan rumus :

$$
M D=\frac{\left|\sum D\right|}{N}
$$

Keterangan:

MD : Mean difference

$\sum \mathrm{D}$ : Jumlah perbedaan dari masing masing pasangan subyek

$\mathrm{N}$ : jumlah subyek

maka nilai $\mathrm{t}$ dapat di cari dengan menggunakan rumus t-test yaitu :

$$
t=\frac{M D}{\sqrt{\frac{\sum_{D}{ }^{2}}{N(N-1)}}}
$$

Keterangan:

MD : Mean different

$\sum \mathrm{D}^{2}:$ deviasi individu dari MD

$\mathrm{N}$ : Jumlah sampel

(Sumber: Sutrisno Hadi, 2000:445) 


\section{HASIL PENELITIAN DAN PEMBAHASAN}

Data-data yang diperoleh dalam pelaksanaan penelitian ini adalah data-data dari hasil latihan passing bawah menggunakan sasaran tembok (wall bounce) dan passing berpasangan menggunakan tali sebagai variabel bebas serta kemampuan passing bawah dalam permainan bola voli klub putra montong baan sebagai variabel terikat.

Selanjutnya untuk mengetahui apakah ada pengaruh latihan passing bawah menggunakan sasaran tembok (wall bounce) dan passing berpasangan menggunakan tali terhadap kemampuan passing bawah dalam permainan bola voli pada subyek penelitian ini.

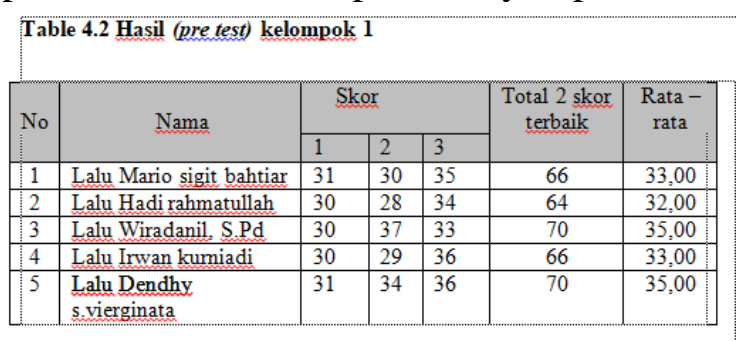

\section{Table 4.3 Hasil (pre test) kelompok 2}

\begin{tabular}{|c|c|c|c|c|c|c|}
\hline \multirow{2}{*}{ No } & \multirow{2}{*}{ Nama } & \multicolumn{3}{|c|}{ Skor } & \multirow{2}{*}{$\begin{array}{l}\text { Total } 2 \text { skor } \\
\text { terbaik }\end{array}$} & \multirow[t]{2}{*}{ Rata -rata } \\
\hline & & 1 & 2 & 3 & & \\
\hline 1 & Lalu Destara & 35 & 37 & 20 & 72 & 36,00 \\
\hline 2 & $\begin{array}{l}\text { Lalu Adi guna } \\
\text { ramdhani }\end{array}$ & 30 & 36 & 30 & 66 & 33,00 \\
\hline 3 & $\begin{array}{l}\text { Lalu Alfiantoro kusuma } \\
\text { putra }\end{array}$ & 36 & 38 & 38 & 76 & 38,00 \\
\hline 4 & Lalu Wira sakti & 36 & 35 & 36 & 72 & 36,00 \\
\hline 5 & $\begin{array}{l}\text { Lalu Muhamad } \\
\text { sindarmawa }\end{array}$ & 35 & 30 & 37 & 72 & 36,00 \\
\hline
\end{tabular}

Table 4.5 Hasil (post test) kelompok 1
\begin{tabular}{|c|l|l|l|l|c|c|}
\hline \multirow{2}{*}{ No } & \multicolumn{2}{|c|}{ Nama } & \multicolumn{2}{|l|}{$\begin{array}{c}\text { Skor } \\
\text { Total 2 skor } \\
\text { terbaik }\end{array}$} & Rata -rata \\
\cline { 2 - 5 } & 1 & 2 & 3 & & \\
\hline 1 & Lalu Destara & 41 & 39 & 41 & 82 & 41,00 \\
\hline 2 & $\begin{array}{l}\text { Lalu Adi guna } \\
\text { ramdhani }\end{array}$ & 38 & 30 & 42 & 80 & 40,00 \\
\hline 3 & $\begin{array}{l}\text { Lalu Alfiantoro } \\
\text { kusuma putra }\end{array}$ & 44 & 30 & 40 & 84 & 42,00 \\
\hline 4 & Lalu Wira sakti & 42 & 30 & 34 & 76 & 38,00 \\
\hline 5 & $\begin{array}{l}\text { Lalu Muhamad } \\
\text { sindarmawa }\end{array}$ & 40 & 38 & 44 & 84 & 42,00 \\
\hline
\end{tabular}

Table 4.6 Hasil (post test) kelompok 2

\begin{tabular}{|c|l|l|l|l|c|c|}
\multirow{2}{*}{ No } & \multicolumn{2}{|c|}{ Nama } & \multicolumn{2}{|l|}{ Skor } & \multirow{2}{*}{$\begin{array}{c}\text { Total 2 skor } \\
\text { terbaik }\end{array}$} & Rata -rata \\
\cline { 3 - 5 } & & 1 & 2 & 3 & & \\
\hline 1 & $\begin{array}{l}\text { Lalu Mario sigit } \\
\text { bahtiar }\end{array}$ & 42 & 38 & 35 & 80 & 40,00 \\
\hline 2 & Lalu Hadi rahmatullah & 37 & 35 & 39 & 76 & 38,00 \\
\hline 3 & Lalu Wiradanil, S.Pd & 42 & 40 & 43 & 85 & 43,00 \\
\hline 4 & Lalu Irwan kumiadi & 38 & 37 & 38 & 76 & 38,00 \\
\hline 5 & $\begin{array}{l}\text { Lalu Dendhy } \\
\text { s.vierginata }\end{array}$ & 39 & 39 & 38 & 78 & 39,00 \\
\hline
\end{tabular}

\section{Uju hipotesis}

Hipotesis yang dirumuskan dalam proses penelitian ini adalah hipotesis alternative $\mathrm{Ha}$ (kerja) yang menyatakan bahwa "Ada pengararuh latihan passing bawah menggunakan sasaran tembok (wall bounce) dan passing berpasangan menggunakan tali terhadap kemampuan passing bawah bola voli pada klub putra Montong Baan Lombok Timur tahun 2019", Hipotesis Ho (nihil) untuk membuktikan apakah hipotesis tersebut terbukti kebenarannya, maka hipotesis kerja tersebut harus dirubah dulu menjadi hipotesis nol sehingga hipotesisnya berbunyi "Ada pengararuh latihan passing bawah menggunakan sasaran tembok (wall bounce) dan passing berpasangan menggunakan tali terhadap kemampuan passing bawah bola voli pada klub putra Montong Baan Lombok Timur tahun 2019".

Dengan kriteria pengujin adalah, apabila t- hitung < t-tabel maka hipotesis nihil (nol) diterima dan hipotesis alternative (h0 ditolak).sedangakan t- hitung > t-tabel, maka hipotesis nihil (h0) ditolak dan hipotesis alternative (ha) diterima.

\section{Menguji nilai t}

Berdasarkan hasil perhitungan t-test maka t-hitung untuk kelompok 1 yaitu 7,751 dan kelompok 2 yaitu 5,517 yang di bandingkan dengan t-tabel pada taraf signifikan $5 \%$ pada derajat kebebasan $n-1 \quad(5-1=4$ yaitu 2.132 sehingga dapat di simpulkan bahwa "ada pengaruh latihan passing bawah menggunakan sasaran tembok (wall bounce) dan passing berpasangan menggunakan tali terhadap kemampuan passing bawah pada klub bola voli putra Montong Baan Lombok Timur tahun 2019.

\section{KESIMPULAN}

Berdasarkan hasil penelitian maka dapat diambil beberapa kesimpulan di antaranya :

1. Terdapat pengaruh latihan passing bawah menggunakan sasaran tembok (wall bounce) terhadap kemampuan passing bawah dalam permainan bola voli klub 
putra Montong Baan Lombok Timur tahun 2019.

2. Terdapat pengaruh latihan passing bawah menggunakan tali dengan passing berpasangan terhadap kemampuan passing bawah dalam permainan bola voli klub putra Montong Baan Lombok Timur tahun 2019

SARAN

Saran yang dapat peneliti berikan terkait hasil penelitian sebagai berikut :

1. Pelatih bola voli putra Montong Baan Lombok timur dapat menerapkan latiha passing bawah menggunakan sasaran tembok (wall bounce) sebaga upaya untuk meningkatkan kemampuan passing bawah para pemainya. Di samping itu pada dasarya latihan passing bawah bawah menggunakan tali dengan passing berpasangan dapat dilakukan sebagai variasi lain agar pemain tidak merasa bosan dengan program latihan yang ada. Namun jika mengacu pada hasil peneitian maka latihan passing bawah menggunakan sasaran tembok (wall bounce) hendaknya lebih di prioritaskan.

2. Untuk peneliti yang akan datang dapat menggunkan hasil penelitian ini sebagai bahan acuan khususnya bagi penelitian sejenis. Peneliti yang akan datang di harapkan dapat mengembangkan metode latihan lain untuk meningkatkan kemampuan teknik dasar pemain dalam bola voli khususnya kemampuan passing.

\section{DAFTAR PUSTAKA}

Ahmadi, Nuril. (2007: 20). Panduan Olahraga Bola Voli. Surakarta : Era Pustaka Utama

Ahmadi, Nuril. (2007: 22). Panduan Olahraga Bola Voli. Surakarta : Era Pustaka Utama

Arikunto, (2015). Hipotesis penelitian. Dalam Diansyah, skripsi (hal. 27). Semarang : Universitas Negeri Malang.

L. Viera (2004: 19). Bola voli yingkat pemula. Jakarta: PT Raja Grafindo Utama Slameto.
M yunus, (1992: 79) Olahraga pilihan bola voli . Jakarta : Depdikbud

Sugiono, (2001 : 64) instrume penelitian, dalam metodologi penelitian pendidikan. Bandung: alfabeta

Sugiyono (2015: 117,118) sampel penelitian. Dalam metode penelitian, Bandung: Alfabeta.

Suharno, (1981). Ilmu Coching umum.Yogyakarta: IKIP Yogyakarta

Sutrisno Hadi, (2000 : 260), Metodologi penelitian, Yogyakarta: Andi Yogyakarta. 